\begin{tabular}{cc}
\hline & Journal of Theoretical and Applied Economics \\
(ISSN:2576-3970)
\end{tabular}

\title{
Studying the Correlation of Stocks via Copula Function
}

\section{Yishuai Tian', Boying Lv', Botao Liu'}

${ }^{1}$ College of Hydraulic \& Environmental Engineering, China Three Gorges University, Yichang 443002, China.

\section{ABSTRACT}

Many factors affect the value of stocks, but there are few studies * ${ }^{*}$ orrespondence to Author: on the correlation between stocks and stock indexes. Therefore, Yishuai Tian this paper selects the closing prices of 4 industries related to University of Chinese Academy Everbright Bank (601818) and 15 sectors related to the market of Social Sciences, 11th, Beijing index from 2017 to 2018, carries on the correlation analysis Fangshan District.

based on the Copula function, and compares the correlation coefficient by calculation. The stocks closely related to Everbright Bank are mainly bank stocks such as Bank of China and Ningbo Bank, while those greatly affected by the Shanghai Composite How to cite this article: Index are Yunnan germanium industry, Tongji Technology, Futian Studying the Correlation of Stocks Automobile and other technology and manufacturing stocks. via Copula Function. Journal of Based on the Copula function to explore the correlation between Theoretical and Applied Economics, stocks and the influencing factors, to provide a specific research $2020 ; 4: 5$ basis for stock correlation analysis.

Keywords: Copula function; Correlation analysis; Stock market index

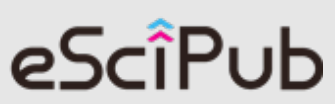

eSciPub LLC, Houston, TX USA.

Website: https://escipub.com/ 


\section{Introduction}

The market price of stocks is not only determined by the value of shares, but also influenced by many other factors, such as the profitability of listed companies, major emergencies, and product market competition [1-4]. Besides, the law of stock price changes is complicated, and a large number of technical indicators and methods are often used for frying stocks. In China, there are k-line charts, market indexes, trend analysis, and morphological Analysis [5], while in the United States, there are dow jones industrial average index and NASDAQ composite index ${ }^{[6]}$. To discuss the stocks affected by other commodities and the stock market index is conducive to the investment of listed companies and to materialize the relationship between stocks and the stock market index. Therefore, it is of considerable significance to dig deeply into the correlation between stocks.

There have been many studies on the correlation and impact of the Analysis of stocks. For example, Song Jia ${ }^{[7]}$ deeply discussed the integration of $R$ \& $D$ and innovation, market competition, and stock performance into a unified whole. Based on the research of A-share listed companies, this paper gives a general conclusion that applies to the Chinese market. Yilun Qian [3] takes Vanke as a typical example, makes an indepth analysis of the factors related to the changes in the stock prices of real estate companies, and finds that the Shanghai Composite Index has a far-reaching impact on it. Hao Ding ${ }^{[8]}$ used the multiple linear regression method to study the factors that affect the stock price of Guizhou Moutai from 2001 to 2016. This paper analyzes the impact of GDP, Shanghai Composite Index, liquor industry output, and the net profit margin of Guizhou Moutai Co., Ltd on Guizhou Moutai stock price. Zongjing Liang et al. ${ }^{[9]}$ aimed at the "clenbuterol" food safety incident that occurred on March 15, 2011, and used Baidu Index as an online attention index. To study the impact of food safety incidents based on the Baidu index on food stock prices in

Shanghai and Shenzhen. Van et al. [10] found that the influence of high-frequency traders on stock price differences is not uniform and varies with the toxicity level of order flow and the number of stocks. The test of Blau ${ }^{[11]}$ shows that religious belief and a lower degree of religious belief and religious belief will harm the volatility of ADR. Gao et al. ${ }^{[12]}$ applied the linear correlation coefficient to quantify the dynamic evolution of the correlation structure between the American market and the Asian market. This paper studies the impact of the 2008 financial crisis on Asian markets. Rubin ${ }^{[13]}$ and others use the latest innovative technologies in the field of network science to analyze the correlation of stock returns and how they evolve. Predecessors have studied how the prices of many stocks are affected by various factors, but at present, there is a lack of case studies on stocks in which a stock is affected by other stocks and related indexes.

In-depth mining of the correlation analysis between stocks has a significant impact on the judgment of the stock market. For this reason, we establish a stock correlation model based on Copula function and take stock of China Everbright Bank (601818) as an example to analyze the correlation. Based on the Copula function model, the correlation coefficients between stocks are calculated and compared. And through the same method, the Shanghai Stock Index and the Shenzhen Stock Index of the large-cap index are selected for correlation analysis. It provides a specific research basis for the correlation analysis of stock price.

\section{Establishment of Stock correlation Model based on Copula function}

As the joint distribution function of uniform distribution, Copula function ${ }^{[14]}$ can connect the edge distribution of several random variables and get their joint delivery. The correlation between the two sets of variables can also be expressed. Therefore, this paper is based on the Copula function to describe the association between stocks and the correlation of the representative index.

The correlation between stocks can be measured by constructing the Copula function of the stock sequence. Because the stock data has the characteristics of -of-theoretical-applied-economics/ 
time-variability, non-stationarity, and complexity, it is difficult to make assumptions about the Copula function describing the structure between variables. Therefore, the nonparametric kernel function is used to estimate the Copula function.

(1) Determining $\mathrm{N}$-element kernel function, Let $X=\left(x_{1}, x_{2}, \ldots, x_{n}\right), Y=\left(y_{1}, y_{2}, \ldots, y_{n}\right)$ variables of

$$
k(z ; h)=\prod_{n=1}^{N} k_{n}\left(\frac{z_{n}}{h_{n}}\right)
$$

Where $h_{n}$ are the width of the kernel function and matrix is as follows:

a positive function of the sample size. The $h_{n}$

$$
h_{n}=\left(\begin{array}{cccc}
h_{1} & 0 & \cdots & 0 \\
0 & h_{2} & \cdots & 0 \\
\vdots & \vdots & \ddots & \vdots \\
0 & 0 & \cdots & h_{n}
\end{array}\right)
$$

(2) Determine the joint distribution density func- , as follows:

tion. The edge density function of time series $X$

$$
\hat{f}_{x}(x)=\frac{1}{n h_{x}} \sum_{t=1}^{n} k_{x}\left(\frac{x-x_{t}}{h_{x}}\right)
$$

The edge density function of time series $Y$, as supports:

$$
\hat{f}_{y}(y)=\frac{1}{n h_{y}} \sum_{t=1}^{n} k_{y}\left(\frac{y-y_{t}}{h_{y}}\right)
$$

The estimated value of the density function of follows:

the edge distribution at the point $\left(x_{t}, y_{t}\right)$, as

$$
\hat{f}(x, y)=\frac{1}{n|h|} \sum_{t=1}^{n}\left(k_{y}\left(\frac{y-y_{t}}{h_{y}}\right) \bullet k_{x}\left(\frac{x-x_{t}}{h_{x}}\right)\right)
$$

The joint distribution function at a point $\left(x_{t}, y_{t}\right)$ is:

$$
\hat{F}(x, y)=\int_{-\infty}^{x} \int_{-\infty}^{y} \hat{f}(x, y) d x d y
$$

(3) Determine the Copula function. According to tion, the value of the Copula function at the point the estimated value of the joint distribution func- $\quad(u, v)$ can be expected to be

$$
\hat{C}(u, v)=\hat{F}\left(f_{x}^{-1}(u), f_{y}^{-1}(v)\right)
$$

Among them,

$f_{z}^{-1}(z)=\inf _{a \in R}(a \mid \hat{F}=(a) \geq z)$.

(4) After determining the correlation function of the time series and obtaining the Copula funccorrelation between the two-time series is as follows: 


$$
\tau_{x y}=4 \int_{0}^{1} \int_{0}^{1} C(u, v) d C(u, v)-1
$$

3. Case Analysis based on Everbright Bank and Market Index

By selecting the stocks of the industries related to the capital or the stock index, and calculating the correlation coefficient between the capital or the stock index and the stocks of the relevant industrial index, we can judge the correlation of the capital. The following is to take the shares of Everbright Bank (601818) as an example to discuss the impact of other stocks on its prices and which stocks are affected by the market index. First of all, select the industries related to Everbright Bank, as well as other influential stocks in the industry. Through the random selection of various types of stocks with a wide range of influence, so as to measure the impact of stocks on the stock index, and select the market index to measure the effect. The Copula function obtains a fluctuation trend ${ }^{[14]}$, which can use different index data, so only the index, the closing price of the stock, is selected to represent the impact on Everbright stock.

3.1 Application of Everbright Bank (601818)

\subsubsection{Selection of related stocks}

CHINA Everbright BANK ${ }^{[15]}$, established in August 1992, is one of the subsidiaries of China Everbright Group and a ministerial company directly under the State Council. It is a financial enterprise approved by the State Council and approved by the people's Bank of China. It is the first national joint-stock commercial bank in China that is state-controlled and has shares in international financial organizations. This paper selects the closing prices of nine typical stocks, such as technology, real estate, energy, and similar banks, such as Bank of China (601988), Shenzhen Huaqiang (000062), and so on. The details are shown in Table 1.

Table 1 selection of stocks related to Everbright Bank

\begin{tabular}{c|c|c}
\hline Serial number & Stock name & Stock type \\
\hline 1 & Bank of China & Financial category \\
2 & PetroChina & Energy category \\
3 & Shenzhen Huaqiang & Manufacturing industry \\
4 & Shenzhen Energy & Energy category \\
5 & Quantum Biology & Science and technology category \\
6 & Ningbo Bank & Financial category \\
7 & Shanghai Electric Power & Energy category \\
8 & Wayne Share & Science and technology category \\
9 & Zhongfang Shares & Manufacturing industry \\
\hline
\end{tabular}

3.1.2 Based on the solution result of Everbright Bank

The closing prices of shares related to Everbright Bank in 2017 and 2018 are substituted into the Copula function to calculate the correlation of the time series. The calculated relationship of each stock is shown in Table 2.

Table 2 Stock correlation

\begin{tabular}{c|c|c}
\hline Ranking & Stock name & Copula correlation coefficient \\
\hline 1 & Bank of China & 0.7852 \\
2 & Ningbo Bank & 0.6659 \\
3 & Shanghai Electric Power & 0.4561 \\
\hline
\end{tabular}




\begin{tabular}{l|c|c}
\hline 4 & Wanye Share & 0.4114 \\
5 & PetroChina & 0.4001 \\
6 & Shenzhen Huaqiang & 0.3910 \\
7 & Shenzhen Energy & 0.1992 \\
8 & Quantum biology & 0.1692 \\
9 & Zhongfang shares & 0.0757 \\
\hline
\end{tabular}

As can be seen from Table 2:

(1) The correlation coefficient of the Bank of China is the largest, and its correlation is the strongest. The shares of companies that go with Everbright Bank have the most significant impact on Everbright Bank shares. The stocks most closely related to Everbright Bank are Bank of China 601988, Ningbo Bank 002142, and Shanghai Electric Power 600021. The closer stocks are Wanye Enterprise 600641, PetroChina 601857, and Shenzhen Huaqiang 0000 62.

(2) The related shares of enterprises in the energy sector have a significant impact on Everbright Bank, and it is the layman's stock that has the most significant effect on Everbright Bank shares in other industries except for banks.

(3) The influence of industrial stocks that have an effect on Everbright Bank shares is ranked from large to small, followed by banking, energy, technology, and real estate.

\subsection{Application of the market index}

\subsubsection{Selection of related stocks}

The market index generally refers to the Shanghai Composite Index of the Shanghai Stock Exchange and the Shenzhen component Index of the Shenzhen Stock Exchange. It can scientifically reflect the situation of the whole stock market, such as the overall rise and fall of the stock or the trend of the stock price. If the market index rises gradually, it can be judged that most stocks are rising. On the contrary, if the index slowly falls, that is, most stocks are falling. ${ }^{[16,17]}$ The market index is calculated by the index of individual stocks because the weight allocated to individual stocks is different, the impact of shares on the index is small and large, affected by a variety of industries. This paper selects 30 representative stocks in 15 main fields, such as the Yunnan germanium industry 002428, Jianglong boat 300589 , and so on. The details are shown in Table 3.

Table 3 selects all kinds of stocks related to the market index

\begin{tabular}{|c|c|c|c|c|c|}
\hline NO. & Domain & Stock name & NO. & Domain & Stock name \\
\hline 1 & $\begin{array}{l}\text { Non-ferrous } \\
\text { metal }\end{array}$ & $\begin{array}{l}\text { Yunnan germa- } \\
\text { nium industry }\end{array}$ & 16 & Environmental tourism & Changbai Mountain \\
\hline 2 & $\begin{array}{l}\text { Construction } \\
\text { business }\end{array}$ & $\begin{array}{c}\text { Tongji science and } \\
\text { technology }\end{array}$ & 17 & Waste utilization & $\begin{array}{l}\text { Dongjiang environmental } \\
\text { protection }\end{array}$ \\
\hline 3 & $\begin{array}{l}\text { Automobile } \\
\text { manufacturing }\end{array}$ & Fukuda Motor & 18 & $\begin{array}{l}\text { Communication equip- } \\
\text { ment }\end{array}$ & Shenyu shares \\
\hline 4 & $\begin{array}{l}\text { Non-ferrous } \\
\text { metal }\end{array}$ & $\begin{array}{l}\text { Guiyan platinum } \\
\text { industry }\end{array}$ & 19 & Food manufacturing & Yili shares \\
\hline 5 & $\begin{array}{l}\text { Financial indus- } \\
\text { try }\end{array}$ & Shanxi Securities & 20 & Delivery equipment & Xinri shares \\
\hline 6 & Education & Kaiyuan shares & 21 & Waste utilization & $\begin{array}{l}\text { Pengqi science and tech- } \\
\text { nology }\end{array}$ \\
\hline 7 & $\begin{array}{l}\text { Environmental } \\
\text { tourism }\end{array}$ & $\begin{array}{c}\text { Shanghai environ- } \\
\text { ment }\end{array}$ & 22 & energy & Shanghai Electric Power \\
\hline 8 & Textile industry & Xinlong Holdings & 23 & Construction business & Kolida \\
\hline 9 & Real estate & Wanye enterprise & 24 & Energy & PetroChina \\
\hline 10 & $\begin{array}{l}\text { Automobile } \\
\text { manufacturing }\end{array}$ & Xinquanshares & 25 & Health & American year health \\
\hline 11 & Communication & Jiuzhiyang & 26 & Education & Kevin education \\
\hline
\end{tabular}




\begin{tabular}{ccc|ccc} 
& equipment & & & \\
12 & Media industry & $\begin{array}{c}\text { Hubei Radio and } \\
\text { Television }\end{array}$ & 27 & Real estate & Yuetaishares \\
13 & $\begin{array}{c}\text { Financial indus- } \\
\text { try }\end{array}$ & Wuxi Bank & 28 & Health & Tiger Medicine \\
& $\begin{array}{c}\text { Delivery equip- } \\
\text { ment }\end{array}$ & Jianglong boat & 29 & Media industry & Visual China \\
15 & Textile industry & Norbangshares & 30 & Food manufacturing & Haitian flavor industry \\
\hline
\end{tabular}

\subsubsection{The solution result of the model}

Because the market index includes Shanghai index and Shenzhen index, this paper calculates the correlation coefficient between Shanghai index and Shenzhen index and the selected stocks respectively, and adds the sum of Shanghai index and Shenzhen index, obtains the Copula value of each stock and the market index, and measures the influence degree of the market index by the combined value. Using MATLAB to achieve the solution of the correlation coefficient, get all the stocks related to the market index, as well as the stocks greatly affected by the market index, the specific ranking and correlation are as follows.

Table 4 the relationship between the market index and all kinds of stocks

\begin{tabular}{ccc|ccc}
\hline Rank & Stock name & value & Rank & Stock name & value \\
\hline 1 & $\begin{array}{c}\text { Yunnan germanium indus- } \\
\text { try }\end{array}$ & 1.3441 & 16 & $\begin{array}{c}\text { Changbai Mountain } \\
\text { Dongjiang environmental }\end{array}$ & 0.9072 \\
& $\begin{array}{c}\text { protection } \\
2\end{array}$ & $\begin{array}{c}\text { Tongji science and technol- } \\
\text { ogy }\end{array}$ & 1.3420 & 17 & 0.8202 \\
3 & Fukuda Motor & 1.3183 & 18 & Shenyushares & 0.7779 \\
4 & Guiyan platinum industry & 1.2276 & 19 & Yili shares & 0.7664 \\
5 & Shanxi Securities & 1.2162 & 20 & Xinri shares & 0.7097 \\
6 & Kaiyuan shares & 1.2103 & 21 & Pengqi science and technol- & 0.7054 \\
7 & Shanghai environment & 1.1604 & 22 & Oghanghai Electric Power & 0.6835 \\
8 & Xinlong Holdings & 1.1393 & 23 & Kolida & 0.6742 \\
9 & Wanye enterprise & 1.1361 & 24 & PetroChina & 0.6108 \\
10 & Xinquan shares & 1.1299 & 25 & American year health & 0.6045 \\
11 & Jiuzhiyang & 0.9915 & 26 & Kevin education & 0.5952 \\
12 & Hubei Radio and Television & 0.9790 & 27 & Yuetaishares & 0.5936 \\
13 & Wuxi Bank & 0.9716 & 28 & Tiger Medicine & -0.0490 \\
14 & Jianglong boat & 0.9323 & 29 & Visual China & -0.4240 \\
15 & Norbang shares & 0.9178 & 30 & Haitian flavor industry & -0.5311 \\
\hline
\end{tabular}

It can be seen from Table 4 that stocks in nonferrous metals, construction, automobile manufacturing, non-ferrous metals, financial industry, education, environmental tourism, textile industry, real estate, and other industries are most affected by the market index. Among them, the Copula value of the Yunnan germanium industry, Tongji science and technology, Futian Automobile, your research platinum industry, Shanxi Securities stocks, and the market index reached more than 1.2, which was greatly affected. The stock correlation values of health, media industry, and food manufacturing industry are nega- tive, indicating that these stocks may have a negative correlation with the market index; that is, the market index rises and stock prices fall.

\section{Result Analysis}

\subsection{The result Analysis of the correlation of Everbright Bank}

The correlation value calculated by the Copula function of the stock closing price of the selected industry is arranged in descending order, the Abscissa represents the ranking number, and the corresponding industrial stock draws a two-dimensional scatter chart as shown in Fig.1. 


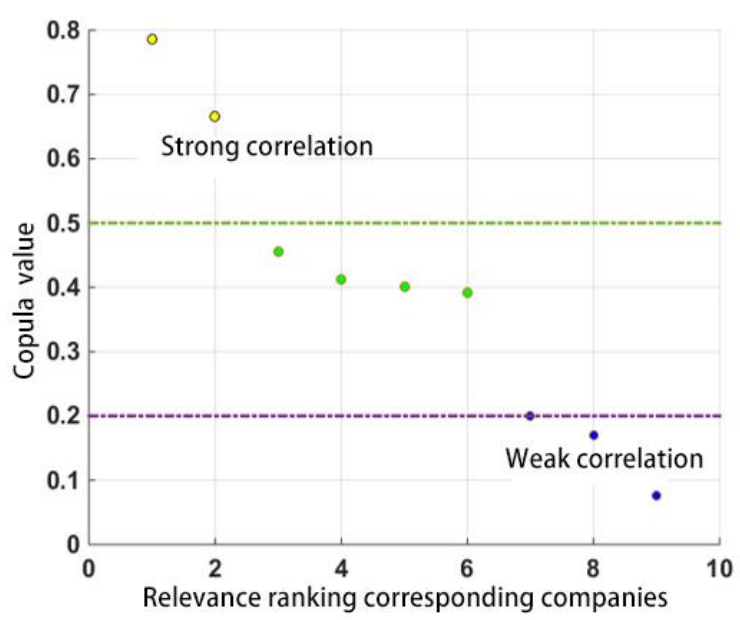

Fig. 1 scatter graph of the correlation between industrial and Everbright stocks

It can be seen from Fig.1 that the yellow distribute represents the industrial stocks of the same industry, that is, the shares of banks. From the figure, we can see that the Copula values of bank stocks are all above 0.6 , and the correlation is powerful. This is because the value transmission power between peer industries is relatively stable, the financial transaction rate is high, and the competition is fierce, resulting in a series of transmission systems, such as stock price influence between each other, market arbitrage, and so on. The blue scatter represents the stocks of the science and technology industry, and it has a weak correlation with the majority of banks, that is, it shows that the market value transmission rate between the technology industry and Everbright bank is low, and the influence-oriented lag is substan- tial. Therefore, due to the influence between listed companies, the impact between stocks is also little.

\subsection{The result Analysis of the correlation of Market Index}

The correlation value calculated by the Copula function of the stock closing price of the selected industry is arranged in descending order, and the Abscissa represents the ranking of stock correlation. According to the range of the value, it can be divided into strong correlation influence, weak correlation influence, and negative correlation influence, that is, $[-1,0]$ is negative correlation influence, $[0,0.8]$ is a weak correlation influence, and $[0.8,1.5]$ is strong correlation influence. The stock of the corresponding industry draws a two-dimensional scatter diagram, as shown in Fig.2.

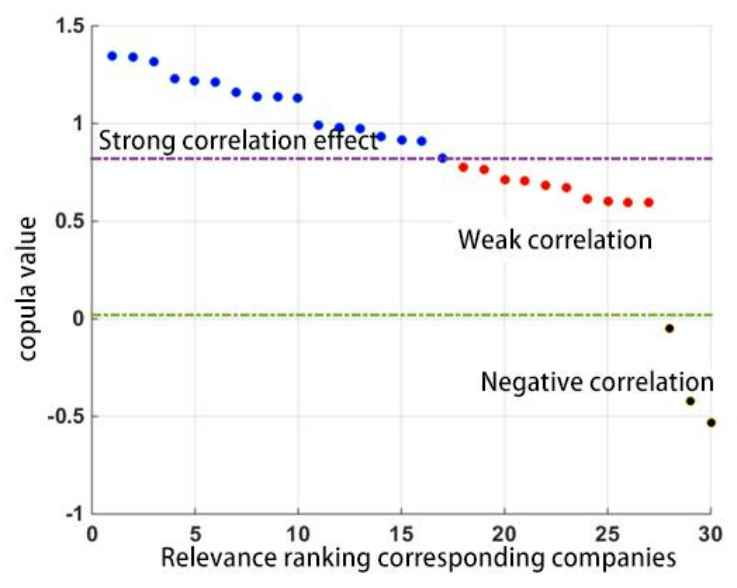

Fig. 2 correlation between industrial stocks and market index 
According to figure 2, we can see that:

(1) The industry categories represented by the blue scatter are the science and technology industry, energy industry, service industry, and manufacturing industry. Because of its emerging characteristics or the nature of crucial social supply, this kind of production has a robust mutual reaction and mutual value transmission with all aspects of society. The market index has a significant impact on the stocks of these industries.

(2) The industry categories represented by the black scatter are the health care industry, food industry, and other related primary industries, which have a stable market value because of their essential contribution characteristics and small elasticity of product demand. Under the background of the weakening Engel coefficient, it is easy to be affected by the negative impact of the stock market environment, that is, the negative correlation with the market index.

\section{Model Evaluation of relationship based on Copula function}

\subsection{Advantages of the model}

(1) Under the condition that it is impossible to determine whether the traditional linear correlation coefficient can correctly measure the correlation between variables, the appearance of the Copula function makes the description of dependence between variables more perfect.

(2) Based on the Copula function model, it has been widely used in the Analysis of relationship between returns on financial assets and financial risk management.

(3) After the establishment of the stock correlation model, combined with the application of specific examples, it shows that the model has good feasibility and can be applied to the correlation analysis of stocks.

\subsection{Model shortcomings}

(1) Lacking the stability analysis of the Copula function model, the testing of the model needs to be strengthened.

(2) The model selects the primary industries related to banks and selects the influential stocks in each sector to analyze the correlation directly. The subjective factors are substantial and can be improved by the algorithm.

\section{Conclusion}

We established a correlation analysis model based on the Copula function. Taking Everbright Bank as an example, it concludes that Bank of China has the strongest correlation with Everbright Bank stock. The stocks of Everbright Bank have the most substantial influence on the shares of banking enterprises, and the related shares of enterprises in the energy sector are the layman stocks that have the most significant impact on them in other industries. Similarly, for the Analysis of the market index, the shares of non-ferrous metals, construction, automobile manufacturing, non-ferrous metals, financial sector, education, environmental tourism, textile industry, real estate, and other industries are most affected by the market index. The stock correlation values of health, media industry, and food manufacturing industry are negative, indicating that these stocks may have a negative correlation with the market index, that is, the market index rises, and stock prices fall. This provides a particular reference for studying the impact of stock prices among stocks and the stocks affected by the market index.

\section{References}

1. Yuan Yao, Beibei Yao, Qi Zhong. A study on the influence of Investor sentiment on Stock return-an empirical Analysis based on Shanghai Ashare data [J]. Price theory and practice, 2019 (05):88-91.

2. Rongyu Deng. The impact of profitability of listed companies on stock prices [J]. The Chinese market,2019(25):42-44.

3. Yilun Qian. Analysis on the influencing factors of Vanke Stock Price-- based on the empirical Analysis of listed companies in Real Estate Industry [J]. Paying taxes, 2019,13(05):166-167. 
4. Huixian Zhang. Study on the relationship between Shanghai Composite Index and other Shanghai Classification Index [J]. Modern Marketing (Information Edition), 2019(01):12.

5. Hanlin Ji, Meng Xu. Research on the dynamic correlation between Financial sector and Shanghai Stock Index-- based on VAR-DCC-GARCH Model [J]. Prices in China, 2020(01):83-85.

6. S\&P Dow Jones Indices; NeoGenomics Set to Join S\&P SmallCap 600[J]. Genetics \& Environmental Business Week, 2019.

7. Jia Song. Product market competition, $R \& D$ investment and stock return [D]. Shanxi University, 2018.

8. Hao Ding. Empirical Analysis on the influencing factors of stock price change in Guizhou Moutai [J]. Modern economic information,2018(12):304.

9. Zongjing Liang, Yonghui Pang, Yun Kuan. Study on the influence of Food Safety incident Network on Food Stock Price [J]. Commercial economy 2019(10):177-180.

10. Van Ness B F, Van Ness R A, Yildiz S. The role of HFTs in order flow toxicity and stock price variance, and predicting changes in HFTs' liquidity provisions[J]. Journal of Economics and Finance, 2017,41(4).

11. Blau B M. Religiosity and the Volatility of Stock Prices: A Cross-Country Analysis[J]. Journal of Business Ethics, 2017,144(3).

12. Gao H, Mei D. The correlation structure in the international stock markets during global financial crisis[J]. Physica A: Statistical Mechanics and its Applications, 2019,534.

13. Rubin D N, Bassett D S, Ready R. Uncovering dynamic stock return correlations with multilayer network analysis[J]. Applied Network Science, 2019,4(1).

14. Boako G, Tiwari A K, Ibrahim M, et al. Analysing dynamic dependence between gold and stock returns: Evidence using stochastic and fullrange tail dependence copula models[J]. Finance Research Letters, 2019,31.

15. Xiaojun Dong. Macro-economy continues to decline and beware of systemic risk agglomeration-- from the listing of China Cinda and Everbright Bank in Hong Kong [J]. Administrative management reform, 2014(04):33-37.

16. Weichen Xing. Prediction of Shanghai Stock Index based on BP neural network [J]. Enterprise Science and Technology and Development, 2019(12):124-125.

17. Bing Xu, Juan Chen. An empirical study on the tail of Index return Distribution in Shanghai and Shenzhen Stock Market [J]. The practice and understanding of mathematics, 2006(09):49-54.

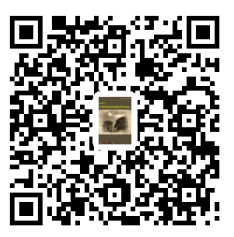

